\title{
PENGARUH TRUST, COMMITMENT, COMMUNICATION DAN CONFLICT HANDLING TERHADAP CUSTOMER LOYALTY NASABAH TABUNGAN PT BANK PANIN TBK DI JAKARTA
}

\author{
Ollie Marcella \\ Program Studi Magister Manajemen Universitas Tarumanagara \\ olliemarcella@gmail.com
}

\begin{abstract}
The purposes of this study are : First, to explore the effect among trust on customer loyalty. Second, to explore the effect among commitment on customer loyalty. Third, to explore the effect among communication on customer loyalty. Fourth, to explore the effect among conflict handling on customer loyalty. The population of this research are all customers of PT Bank Panin Tbk savings in Jakarta. The Samples are collected from PT Bank Panin Tbk's savings customers in South Jakarta. The method of data collection is crosssectional design with 150 respondents. The technique of data analysis used in this study was multiple regression analysis. The results are : (a) trust has a positive effect toward customer loyalty; (b) commitment has not positive effect toward customer loyalty; (c) communication has a positive effect toward customer loyalty; (d) conflict handling has a positive effect on customer loyalty.
\end{abstract}

Keywords : trust, commitment, communication, conflict handling, customer loyalty.

\section{PENDAHULUAN}

Kesuksesan suatu bank tentunya tidak dapat dipisahkan dari nasabah yang menjadi target utama sebagai sumber pendapatan bagi bank. Tanpa adanya nasabah yang melakukan transaksi maka keberlangsungan bank berangsur menurun dan menimbulkan kerugian. Dalam ketatnya persaingan dunia perbankan serta nasabah yang semakin pintar, bank harus meningkatkan hubungan dengan nasabah dan membangun loyalitas nasabah (Tam,2012). Menurut Griffin (2005), loyalitas dapat didefinisikan berdasarkan perilaku membeli, nasabah yang loyal adalah orang yang, melakukan pembelian berulang secara teratur, membeli antar lini produk atau jasa, merefrensikan kepada orang lain dan menunjukkan kekebalan terhadap tarikan dari pesaing. Loyalitas nasabah atau customer loyalty merupakan puncak pencapaian dari pelaku bisnis dalam memenangkan persaingan khususnya di bidang perbankan.

Loyalitas pelanggan dapat menjadi nilai pendukung dalam meningkatkan keberhasilan perusahaan di masa depan. Menurut Oliver (1997) menjelaskan loyalty sebagai komitmen yang dipegang teguh konsumen secara konsisten untuk melakukan pembelian kembali atas pilihan produk atau jasa di masa depan. Faktor-faktor yang memengaruhi customer loyalty yaitu customer satisfaction merupakan suatu tingkatan dimana kebutuhan, keinginan dan harapan dari pelanggan dapat terpenuhi yang akan mengakibatkan terjadinya pembelian ulang atau kesetiaan yang berlanjut (Band, 1991). Customer satisfaction dapat memengaruhi tingkat loyalitas nasabah pada sebuah perusahaan. Customer Experience Management, konsep CEM merupakan konsep pengembangan dari konsep CRM. Menurut Ndubisi (2007) faktor yang dapat mempengaruhi loyalitas nasabah adalah relationship marketing yang terdiri dari trust, commitment, communication, dan conflict handling.

Trust (kepercayaan) dapat dibangun oleh perusahaan dengan cara menepati janji terhadap pelanggan, mampu memberikan keamanan dalam setiap transaksi yang pelanggan lakukan, mampu memberikan pelayanan yang berkualitas, menunjukkan sikap peduli terhadap pelanggan, serta memberikan rasa aman, sehingga akan mempengaruhi loyalitas 
pelanggan terhadap perusahaan semakin meningkat. Nelson Oly Ndubisi (2006) menemukan trust memiliki pengaruh yang signifikan terhadap customer loyalty.

Selain trust, customer loyalty juga dipengaruhi commitment. Menurut Capel dan Ndubisi (2011) komitmen merupakan komponen penting dari relationship marketing, dan merupakan titik ukur penting untuk mengetahui seberapa besar customer loyalty dan frekuensi pembelian dari seorang pelanggan. Melisa Hadinata (2013) yang menyatakan bahwa commitment memiliki pengaruh yang signifikan terhadap customer loyalty.

Pride dan Ferrel (2010) mendefisinikan communication adalah sebuah kegiatan berbagi makna melalui pengiriman informasi. Menurut Imam Nuryanto (2010), komunikasi memiliki pengaruh signifikan terhadap customer loyalty, hal ini dapat menunjukkan bahwa communication yang dilakukan oleh perusahaan dengan cara memberikan informasi yang tepat dan dapat dipercaya serta informasi mengenai adanya perubahan jasa yang ditawarkan, dan komunikasi yang proaktif ketika terjadi masalah antara perusahaan dengan pelanggan, maka pelanggan akan merasa aman dan percaya karena pelanggan dengan mudah memperoleh informasi yang mereka inginkan sehingga akan meningkatkan loyalitas pelanggan terhadap perusahaan.

Menurut Deni Panji Setiyoko (2013), conflict handling memiliki pengaruh positif dan signifikan terhadap customer loyalty, hal ini dapat menunjukkan bahwa ketika perusahaan mampu menangani konflik, memberikan solusi secara terbuka dengan pelanggan dan menangani masalah dengan cepat, maka kepercayaan dan kualitas hubungan antara perusahaan dengan pelanggan akan semakin meningkat. Hal tersebut juga sama diungkapkan oleh Imam Nuryanto (2010) yang menyatakan bahwa conflict handling memiliki pengaruh yang signifikan terhadap customer loyalty.

Tujuan dari penelitian ini adalah untuk mengetahui : (1) pengaruh trust terhadap customer loyalty; (2) pengaruh commitment terhadap customer loyalty; (3) pengaruh communication terhadap customer loyalty; (4) pengaruh conflict handling terhadap customer loyalty. Hasil penelitian ini diharapkan dapat memberikan informasi kepada perusahaan dalam pengambilan keputusan untuk mempertahankan customer loyalty dengan penggunaan faktor trust, commitment, communication dan conflict handling.

\section{KAJIAN TEORI}

Trust. Menurut Dharmmestha (2005:57), trust didefinisikan sebagai "Trust are the willingness to rely on others who are involved in the exchange because he has faith in the other party, trust is a common hope that individuals have words that arise form others are reliable". Rofiq (2007:32) mengungkapkan bahwa "Trust is belief of a particular party against another in conducting a transaction relationship based on a belief that the person who is believes it has all the obligations well as expected". Trust diartikan sebagai kesediaan untuk mengandalkan kemampuan, integritas, dan motivasi pihak lain untuk bertindak dalam rangka memuaskan kebutuhan dan kepentingan seseorang sebagaimana disepakati bersama secara implisit maupun eksplisit (Sheth dan Mittal dalam Tjiptono, 2011:516). Dari definisi di atas, trust adalah kepercayaan yang diberikan konsumen kepada Bank dalam bertindak yang telah disepakati bersama.

Commitment. Menurut Tjiptono (2011:516) "komitmen merupakan hasrat atau keinginan kuat untuk mempertahankan dan melanjutkan relasi yang dipandang penting dan bernilai jangka panjang". Komitmen merupakan komponen penting dari relationship marketing, dan merupakan titik ukur penting untuk mengetahui seberapa besar customer loyalty dan frekuensi pembelian dari seorang pelanggan (Capel dan Ndubisi, 2011). Menurut Moorman, Desphande dan Zaltmen (1992) yang dikutip Fenny dan Nathania (2005:60), komitmen 
adalah sebagai keinginan untuk mempertahankan dan memperoleh nilai relationship (hubungan). Menurut Morgan dan Hunt (1994:23) "Commitment is control to all the rational exchange between the firm and its various partners". Menurut Melisa Hadinata (2013), commitment memiliki pengaruh paling besar terhadap terciptanya customer loyalty. Berdasarkan definisi di atas, commitment adalah tindakan yang dilakukan Bank kepada konsumen secara konsisten dalam memberikan pelayanan yang terbaik.

Communication. Anderson dan Robert (2001:105) "Communication is defined as the interchange of thought or information between two or more persons to bring about mutual understanding”. Komunikasi adalah tugas perusahaan pada tahap awal untuk membangun kesadaran, mengembangkan preferensi konsumen (dengan mempromosikan nilai, kinerja dan fitur), meyakinkan pembeli, dan mendorong calon konsumen untuk membuat keputusan pembelian (Ndubisi, 2007 ). Komunikasi menurut Kotler (2005) adalah suatu proses pertukaran informasi antar individu ataupun konsumen melalui suatu system yang lazim (biasa), baik dengan simbol, sinyal maupun perilaku atau tindakan. Komunikasi bisnis (Purwanto,2006) adalah komunikasi yang digunakan dalam dunia bisnis yang mencakup berbagai macam bentuk komunikasi, baik komunikasi verbal maupun komunikasi non verbal untuk mencapai tujuan tertentu. Berdasarkan definisi di atas, communication adalah suatu hubungan yang dibangun antara perusahaan dengan pelanggan guna menjembatani persepsi pelanggan terhadap perusahaan yang akhirnya membuat keputusan pembelian terjadi.

Conflict Handling. Menurut Selnes (1998:56) "Conflict handling was defined as the supplier's ability to minimize the negative consequences of manifested and potential conflicts". Ndubisi (2007) menyimpulkan bahwa kemungkinan timbulnya kasus-kasus tertentu tergantung pada tingkat kepuasan hubungan yang tercipta sebelumnya, besarnya harapan pelanggan dalam suatu hubungan, dan evaluasi alternatif yang tersedia. Pemulihan pelayanan juga bisa ditangani dengan sangat baik ketika dipandang sebagai satu kesempatan bukan sebagai suatu pilihan sulit. Keluhan pelanggan merupakan kesempatan untuk memperkuat hubungan (Bramson, 2004). Berdasarkan definisi di atas, conflict handling adalah tindakan yang dilakukan Bank kepada konsumen dalam memberikan solusi di setiap permasalahan.

Customer Loyalty. Definisi Customer Loyalty menurut Oliver (2014:432) adalah “Customer loyalty is deeply held commitment to rebuy or repatronize a prefered product or service consistently in the future, despite situational influences and marketing efforts having the potential to cause switching behaviour". Definisi Customer Loyalty menurut Spreng, Mackenzie, dan Olshvskhy (1996:102) "the peak of business achievement within a company". Loyalitas nasabah tidak terlepas dari kepuasan pelanggan adalah perasaan (feeling) yang dirasakan pembeli dari kinerja perusahaan yang memenuhi harapan mereka. Dari definisi di atas, loyalitas nasabah merupakan feedback positif yang berupa pembelian yang dilakukan secara berulang terhadap produk/jasa dan dapat mereferensikan terhadap calon pelanggan lain.

Pengaruh Trust, Commitment, Communication dan Conflict Handling terhadap Customer Loyalty. Menurut Deni Panji (2013), trust berpengaruh positif terhadap customer loyalty. Hal ini dapat menunjukkan bahwa ketika trust (kepercayaan) dapat dibangun oleh perusahaan dengan cara menepati janji terhadap nasabah, mampu memberikan keamanan dalam setiap transaksi yang nasabah lakukan, mampu memberikan pelayanan yang berkualitas, menunjukkan sikap peduli terhadap nasabah, serta memberikan rasa aman. Hal yang serupa juga dinyatakan oleh Melisa Hadinata berdasarkan penelitian yang dilakukannya, 
bahwa trust memiliki pengaruh terhadap customer loyalty, semakin besar kepercayaan di bank, semakin tinggi tingkat loyalitas nasabah.

Deni Panji (2013), menyatakan bahwa commitment berpengaruh positif terhadap customer loyalty. Hal ini dapat menunjukkan bahwa ketika commitment yang dibangun oleh perusahaan dengan melakukan penyesuaian secara terus-menerus untuk menyediakan kebutuhan nasabah dan meningkatkan kualitas layanan maka hal tersebut dapat memberikan kepuasan bagi nasabah yang pada akhirnya akan membawa pada terciptanya hubungan yang erat antara perusahaan dengan nasabah, sehingga akan mempengaruhi loyalitas nasabah.

Communication memiliki pengaruh yang signifikan terhadap customer loyalty. Hal ini didukung cara memberikan informasi yang tepat dan dapat dipercaya serta informasi mengenai adanya perubahan jasa yang ditawarkan, dan komunikasi yang proaktif ketika terjadi masalah antara perusahaan dengan nasabah, maka nasabah akan merasa aman dan percaya karena nasabah dengan mudah memperoleh informasi yang mereka inginkan sehingga akan mempengaruhi loyalitas nasabah (Deni Panji, 2013). Hal serupa dinyatakan oleh Melisa Hadinata, communication memiliki pengaruh signifikan terhadap customer loyalty.

Menurut Chan (2007) menemukan hubungan yang signifikan antara penyelesaian masalah dan loyalitas pelanggan secara tidak langsung melalui kepercayaan dan kualitas hubungan dirasakan. Kemampuan bank untuk menangani konflik dengan baik juga secara langsung akan mempengaruhi loyalitas pelanggan. Hal serupa dinyatakan oleh Melisa Hadinata, berdasarkan hasil penelitiannya bahwa bahwa conflict handling memiliki pengaruh signifikan terhadap customer loyalty. Berdasarkan paparan di atas, maka hipotesis penelitian adalah sebagai berikut :

H1 :Terdapat pengaruh positif antara trust terhadap customer loyalty

H2 : Terdapat pengaruh positif antara commitment terhadap customer loyalty

H3 : Terdapat pengaruh positif antara communication terhadap customer loyalty

H4 : Terdapat pengaruh positif antara conflict handling terhadap customer loyalty

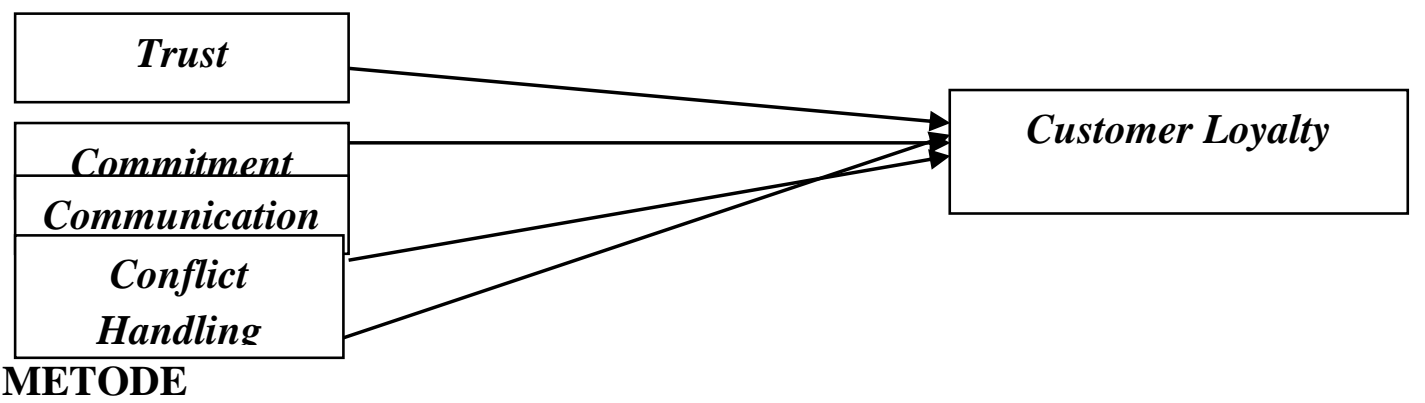

Populasi, Teknik Pemilihan Sampel, dan Ukuran Sampel. Populasi dalam penelitian ini adalah seluruh nasabah tabungan PT Bank Panin Tbk di Jakarta. Sampel diperoleh dari nasabah tabungan PT Bank Panin Tbk di Jakarta Selatan yang sudah menjadi nasabah Bank Panin minimal selama 1 tahun agar dapat mencapai tujuan penelitian. Metode pengambilan sampel dalam penelitian ini adalah teknik cross-sectional design merupakan desain pengumpulan data sampel dari suatu populasi yang hanya dilakukan sekali dalam satu waktu. Ukuran sampel yang digunakan dalam penelitian ini sebanyak 150 responden nasabah tabungan PT Bank Panin Tbk di Jakarta Selatan.

Variabel dan Pengukuran. Pada penelitian ini variabel trust, commitment, communication dan conflict handling merupakan variabel bebas, sedangkan customer loyalty merupakan variabel terikat.

Tabel 1. Variabel dan Pengukuran 


\begin{tabular}{lll}
\hline Variabel & Jumlah Item & Sumber \\
\hline Variabel Bebas & & \\
1. Trust & 6 & Nelson Oly Ndubisi (2005) \\
2. Commitment & 4 & Nelson Oly Ndubisi (2005) \\
3. Communication & 5 & Nelson Oly Ndubisi (2005) \\
4. Conflict Handling & 3 & Nelson Oly Ndubisi (2005) \\
5. Customer Loyalty & 9 & Lewis \& Soureli (2006), \\
& & Jones \&Taylor (2007), \\
& & Baumann et al. (2007). \\
\hline
\end{tabular}

Metode Analisa Data. Metode analisis data yang digunakan untuk menjawab masalah penelitian ini adalah dengan menggunakan analisis regresi berganda. Uji asumsi seperti uji normalitas, uji multikolineritas dan uji heterokedastisitas telah dilakukan sebelum analisis regresi berganda dilakukan dan hasilnya menunjukkan semua asumsi sudah terpenuhi. Taraf signifikansi yang digunakan dalam penelitian ini adalah 5\%. Pengujian dalam penelitian ini menggunakan program SPSS (Statistical Package for Social Science).

Pada penelitian ini, pengujian untuk analisis data dilakukan dengan membagi menjadi 4 hipotesis, hipotesis pertama yaitu menguji pengaruh trust terhadap customer loyalty, hipotesis kedua yaitu menguji pengaruh commitment terhadap customer loyalty, hipotesis ketiga yaitu menguji pengaruh communication terhadap customer loyalty dan hipotesis keempat yaitu menguji pengaruh conflict handling terhadap customer loyalty.

\section{HASIL DAN PEMBAHASAN}

Tabel 2 berikut merupakan hasil uji validitas dan reliabilitas semua variabel penelitian :

Tabel 2. Hasil Uji Validitas dan Reliabilitas

\begin{tabular}{|c|c|c|c|}
\hline Variabel & Item & $\begin{array}{c}\text { Corrected item-total } \\
\text { correlation }\end{array}$ & Cronbach Alpha \\
\hline \multirow{6}{*}{ Trust } & $\begin{array}{l}\text { Bank X melindungi } \\
\text { transaksi saya }\end{array}$ & 0,674 & \multirow{4}{*}{0,896} \\
\hline & $\begin{array}{l}\text { Saya mengandalkan } \\
\text { Bank X }\end{array}$ & 0,661 & \\
\hline & $\begin{array}{l}\text { Bank X konsisten } \\
\text { dalam memberikan } \\
\text { perlindungan }\end{array}$ & 0,744 & \\
\hline & $\begin{array}{l}\text { Pegawai Bank X } \\
\text { hormat kepada } \\
\text { nasabah }\end{array}$ & 0,743 & \\
\hline & $\begin{array}{l}\text { Saya percaya dengan } \\
\text { pelayanan yang } \\
\text { diberikan }\end{array}$ & 0,752 & \\
\hline & $\begin{array}{l}\text { Bank memenuhi } \\
\text { kewajibannya kepada } \\
\text { nasabah }\end{array}$ & 0,745 & \\
\hline \multirow[t]{2}{*}{ Commitment } & $\begin{array}{l}\text { Bank memberikan } \\
\text { apa yang saya } \\
\text { butuhkan }\end{array}$ & 0,634 & \multirow[t]{2}{*}{0,776} \\
\hline & $\begin{array}{l}\text { Bank memberikan } \\
\text { layanan personal bagi } \\
\text { nasabah }\end{array}$ & 0,634 & \\
\hline
\end{tabular}




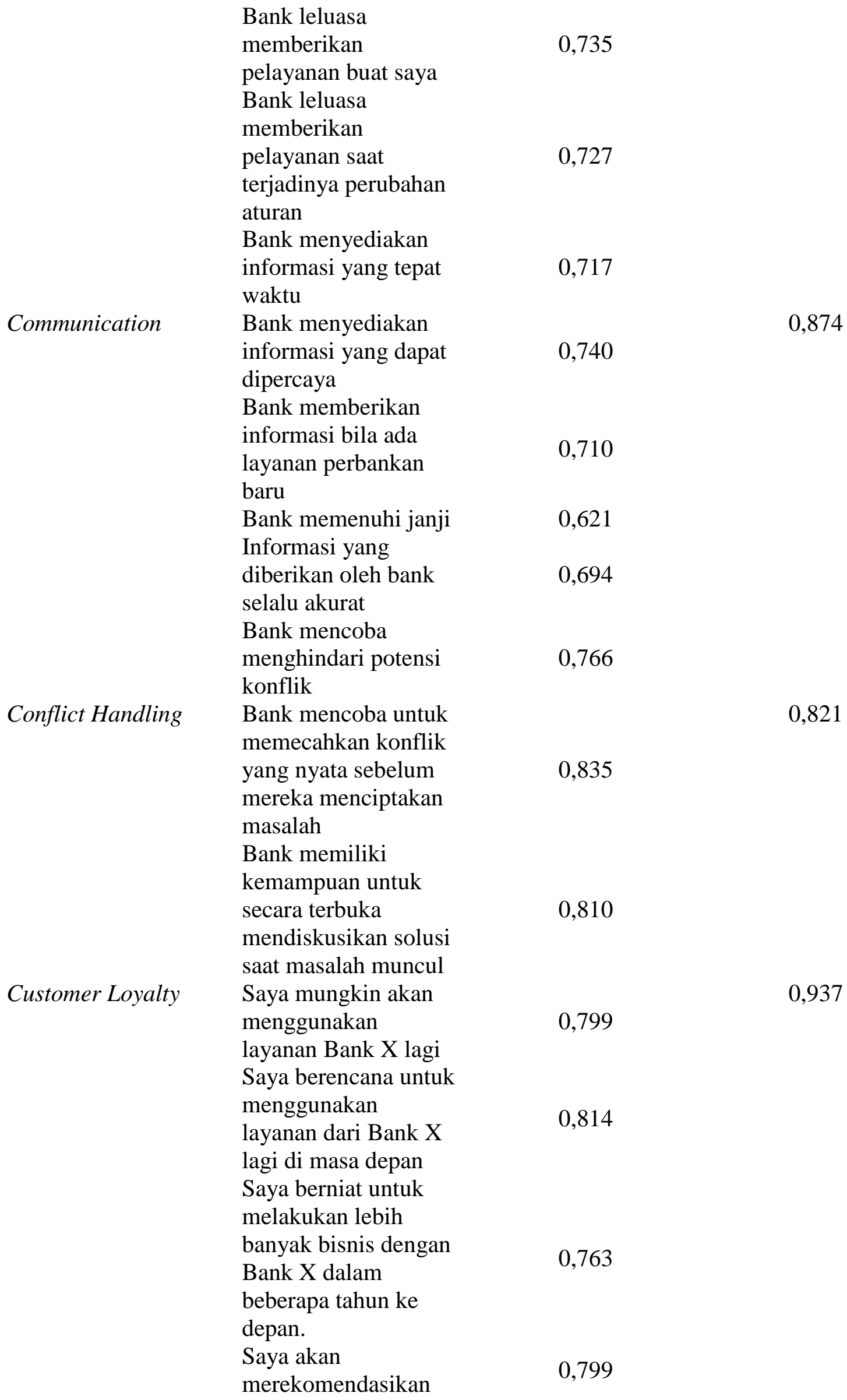




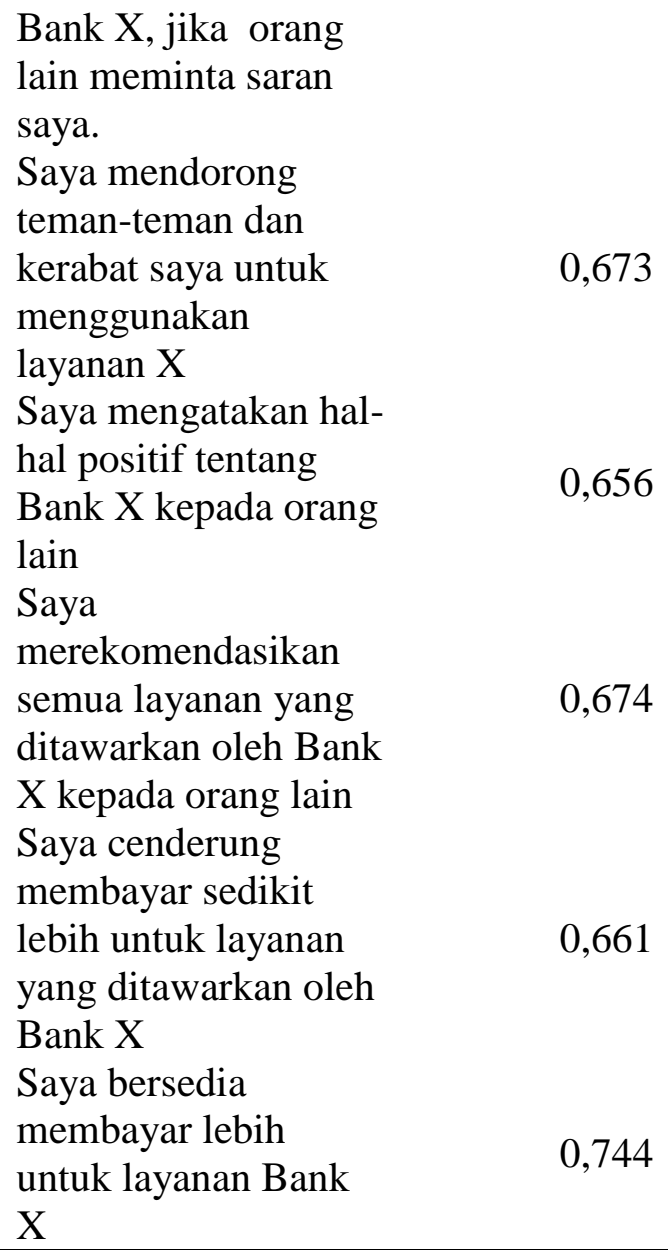

Hasil uji validitas menunjukkan bahwa nilai corrected item total correlation semua butir pernyataan pada setiap variabel penelitian lebih besar dari 0,3, dengan demikian dapat ditarik kesimpulan bahwa semua pernyataan pada trust, commitment, communication, conflict handling dan customer loyalty adalah valid. Sementara hasil dari pengujian reliabilitas seluruh variabel pada penelitian ini diperoleh nilai Cronbach Alpha setiap variabel > 0,6, maka dapat disimpulkan bahwa seluruh variabel yang digunakan dalam penelitian ini reliabel.

Profil Responden. Berdasarkan data yang telah dikumpulkan pada penelitian ini sebagian besar responden dalam penelitian berjenis kelamin pria 52\%, berusia 21 - 30 tahun sebesar $55,30 \%$, berpendidikan terakhir S1 sebesar 65,3\%, memiliki pekerjaan sebagai pegawai swasta/negeri sebesar 58\%, berpendapatan Rp.3.000.000.000 - Rp.9.999.999 sebesar 48\%, merupakan nasabah Bank Panin sebesar 96,70\%, sudah menjadi nasabah Bank Panin selama 1 tahun sebesar 91,30\%, melakukan transaksi 2 minggu sekali sebesar 47,3\% dan melakukan setor dana $<4$ kali/bulan sebesar $58 \%$.

Hasil pengujian hipotesis secara parsial (uji-t) pada Tabel 3 menunjukkan bahwa trust $\left(\mathrm{H}_{1}\right)$, communication $\left(\mathrm{H}_{3}\right)$ dan conflict handling $\left(\mathrm{H}_{4}\right)$ memiliki pengaruh positif dan signifikan terhadap customer loyalty. Hal ini dikarenakan bahwa pelanggan memiliki loyalitas yang tinggi terhadap perusahaan karena kepercayaan yang diberikan pelanggan terhadap perusahaan, komunikasi yang baik dan terbuka dari perusahaan ke pelanggan serta penyelesaian masalah yang terbuka. Namun, commitment $\left(\mathrm{H}_{2}\right)$ tidak memiliki pengaruh positif dan signifikan terhadap customer loyalty. 
Tabel 3. Hasil Pengujian Hipotesis

\begin{tabular}{lllll}
\hline & Hipotesis & B & Sig. & Kesimpulan \\
\hline H1 & $\begin{array}{l}\text { Terdapat pengaruh positif } \\
\text { antara trust terhadap } \\
\text { customer loyalty }\end{array}$ & 0,393 & 0,007 & Tidak Ditolak \\
H2 & $\begin{array}{l}\text { Terdapat pengaruh positif } \\
\text { antara commitment terhadap } \\
\text { customer loyalty } \\
\text { Terdapat pengaruh positif } \\
\text { antara communication } \\
\text { terhadap customer loyalty } \\
\text { Terdapat pengaruh positif } \\
\text { antara conflict handling } \\
\text { terhadap customer loyalty }\end{array}$ & $-0,037$ & 0,928 & Ditolak \\
H4 & 0,907 & 0,000 & Tidak Ditolak \\
\hline
\end{tabular}

Hasil penelitian vaiabel secara parsial, variabel (X1) trust sama dengan penelitian yang dilakukan oleh Deni Panji, trust berpengaruh positif terhadap customer loyalty. Trust dapat diartikan bahwa nasabah memberikan rasa percaya nya terhadap Bank dalam menyimpan, mengelola serta memberikan jaminan keamanan. Menurut Singh, Sideshmuskh (2000) dan Garbarino, Johnson (1999), jika pelanggan tidak mempercayai perusahaan, mereka tidak akan menempatkan pembelian pertama, apalagi pembelian berikutnya setelah pembelian pertama, kepercayaan adalah salah satu hal yang bertanggung jawab atas komitmen konsumen dalam melakukan pembelian kedua atau ketiga (dan dengan perusahaan yang sama) dan, secara umum, secara konsisten mengulangi pembelian. Variabel (X2) commitment tidak sama dengan penelitian Ndubisi (2006) Budi Prabowo (2008), Imam Nuryanto (2010), Deni Panji Setiyoko (2013) yang menjelaskan bahwa commitment memiliki pengaruh yang signifikan terhadap customer loyalty. Hal ini juga tidak sama dengan penelitian yang dilakukan Melisa Hadinata (2013) yang menyatakan variabel commitment merupakan faktor terkuat dalam memengaruhi customer loyalty. Tolak ukur commitment tentunya berbeda-beda oleh setiap individu masalah. Pernyataan dalam kuesioner mengenai commitment, hanya mencakup 2 pernyataan yang belum tentu mewakili apa yang dirasakan nasabah. Komitmen merupakan salah satu variabel yang dapat meningkatkan loyalitas nasabah, pernyataan kuesioner meliputi Bank Panin memberikan apa yang dibutuhkan nasabah serta memberikan layanan personal bagi nasabah. Pernyataan pertama mengenai memberikan apa yang dibutuhkan nasabah, tentunya menimbulkan makna yang ambigu, yang dibutuhkan nasabah belum tentu termasuk dalam SOP Bank Panin. Variabel (X3) menurut Deni Panji, communication memiliki pengaruh yang signifikan terhadap customer loyalty. Communication merupakan hubungan yang dibangun oleh Bank Panin kepada nasabah, dengan menyediakan informasi akurat dan tepat waktu, menyediakan informasi terbaru serta menepati janji. Bentuk komunikasi yang dilakukan Bank Panin dapat melalui media, selain itu komunikasi personal jauh lebih efektif menjangkau nasabah, salah satu nya dengan adanya divisi marketing. Variabel (X4) Menurut Deni Panji, conflict handling memiliki pengaruh yang signifikan terhadap customer loyalty. Hal yang sama dinyatakan juga oleh Melisa Hadinata (2013) dan Nadira Artantie (2013) bahwa conflict handling memiliki pengaruh positif dan signifikan terhadap customer loyalty. Hasil hipotesis variabel conflict handling memiliki faktor terkuat dalam memengaruhi customer loyalty. Conflict Handling yaitu pelayanan penyelesaian masalah yang dilakukan Bank Panin terhadap nasabah, hal ini dapat ditunjukkan Bank Panin dengan cara menghindari konflik, menyelesaikan konflik serta dapat berdiskusi dengan nasabah saat masalah terjadi. 


\section{PENUTUP}

Simpulan. Salah satu cara Bank untuk dapat bertahan menghadapi persaingan adalah dengan cara mempertahankan nasabah yang sudah ada atau melakukan transaksi secara kontinu dibandingkan mencari nasabah baru. Tidak hanya inovasi produk dalam suku bunga deposito maupun kredit, tetapi kepercayaan dari nasabah, komitmen dari bank untuk memberikan pelayanan terbaik, komunikasi yang baik dan terbuka dengan nasabah serta penanganan konflik yang baik sangat berperan penting dalam meningkatkan loyalitas nasabah.

Hasil penelitian ini membuktikan trust memiliki pengaruh yang signifikan terhadap customer loyalty, yakni nasabah memberikan kepercayaan Bank dalam melindungi transaksi yang dilakukan, serta memenuhi kewajibannya sebagai Bank (menghimpun, mengelola serta menyalurkan kredit ke masyarakat). Commitment tidak memiliki pengaruh yang signifikan terhadap customer loyalty, hal ini dapat terjadi dikarenakan tolak ukur commitment dalam kuesioner adalah mengenai pelayanan Bank terhadap nasabah, yang dapat menimbulkan persepsi yang berbeda di setiap nasabah. Artinya pelayanan bank yang diberikan kepada nasabah tidak ada indikatornya. Communication memiliki pengaruh yang signifikan terhadap customer loyalty, hal ini dapat terjadi karena komunikasi merupakan hubungan yang dibangun antara Bank dan nasabah, komunikasi yang dibangun juga harus baik dan terbuka sehingga tidak terjadi kesalahpahaman. Dan conflict handling memiliki pengaruh yang signifikan terhadap customer loyalty, hal ini dapat terjadi karena nasabah melihat bagaimana penanganan bank dalam menghadapi masalah. Tentunya penanganan masalah serta menghindar dari konflik dapat meningkatkan loyalitas nasabah.

Saran. Hasil penelitian ini diharapkan dapat memberikan saran kepada pihak Bank agar dapat memperhatikan faktor trust, communication dan conflict handling dalam kegiatan operasi dan pelayanannya, dikarenakan telah terbukti oleh penelitian yang telah dilakukan bahwa faktor-faktor tersebut menjadi kontribusi yang sangat berpengaruh dalam menciptakan loyalitas nasabah. Untuk faktor commitment dapat diperhatikan lebih seksama oleh Bank agar dapat memberikan pelayanan terbaik bagi nasabah. Bagi peneliti lain, disarankan agar jangkauan pengambilan sampel dan cakupan wilayah diperluas lagi untuk penelitian selanjutnya, sehingga dapat memperkuat dan melengkapi penelitian sebelumnya serta menambah variabel-variabel lainnya seperti customer satisfaction, customer experience management.

\section{DAFTAR RUJUKAN}

Ainur, Rofiq. (2007). Pengaruh Dimensi Kepercayaan (Trust) Terhadap Partisipasi Pelanggan E-Commerce. (Studi Pada Pelanggan E-Commerce Di Indonesia), Tesis, Program Pasca Sarjana Fakultas Ekonomi Universitas Brawijaya. Malang.

Band, William A. (1991). Crafeting Value for Customer. Jhon willey and Sons Inc : New York.

Bramson. (2004). From the Marketing Mix to Relationship Marketing : Towards a Paradigm Shift in Marketing. Journal of Management Decisions, Vol. 44 No.3.

Chan, Syafruddin. (2003). Relationship Marketing : Inovasi Pemasaran yang Membuat Pelanggan Bertekuk Lutut. Jakarta : PT. Gramedia Pustaka Utama.

Dharmmestha. (2005). Loyalitas Pelanggan Sebuah Kajian Konseptual Sebagai Panduan. Jurnal Ekonomi dan Bisnis Indonesia.

Griffin, Jill. (2005). Customer Loyalty : Menumbuhkan dn Mempertahankan Kesetiaan Pelanggan. Jakarta : Erlangga.

Kotler dan Keller. (2009). Manajemen Pemasaran. Jilid I. Edisi ke 13. Jakarta: Erlangga. 
Kotler,P., \& Armstrong, G. (2012). Principles of Marketing Fourteen Edition. Pearson.

Kotler, Philip, Thomas Hayes dan Bloom Paul. (2002). Marketing Professional Service. Pretince Hall International Press.

Moorman, C., Zaltman, G., \& Deshpande, R. (1992). Relationship Between Providers and Users of Market Research: The Dynamics of Trust Within and Between Organization. Journal of Marketing Vol.29, No.3, pp.314-328.

Nelson Oly Ndubisi. (2006). Relationship Marketing and Customer Loyalty. Marketing Intelligence \& Planning, Vol.25 Issue : 1, pp.98-106.

Oliver, Riscrd L. (1997). Satisfaction A Behavioral Perspective On The Consumer. McGrawHill Education, Singapore.

Pride, William M dan O.C. Ferrel. (2010). Marketing. Fiftinth Edition, Canada : Sourth Western International Edition.

Selnes, F. (1998). Antecedents and Consequences of Trust and Satisfaction in Buyer-Seller Relationship. European Journal Of Marketing, Vol.32 No. 3/4, pp. 305-322.

Spreng, R,. MacKenzie. \& Olshavsky. (1996). A Re-examination of the determinants of customer satisfaction. Journal of Marketing, 60 (3), 15-32.

Tjiptono, Fandy. (2007). Strategi Bisnis Pemasaran. Yogyakarta: Andi. 
